\section{Artificial Intelligence and its Implications for Bcation}

\section{By Laura Kann}

Introduction

Twenty-two years ago the study of ar(Aicial intelligence (AI) had barely begun to crawl. An area of study fraught with
controversy, diversity, and decentralized progress has been made. AI is just now reaching the point whereby it can have crucial implications for all aspects of life. ment, recreation, health care and education will all be affected. This article will focus on the educational implications of AI, now and in the near future. Specific
uses of AI will be illustrated and the issues surrounding these uses evaluated.
However, in order to facilitate a more accurate perception of the issues and to provide equal footing from which to base somewhat philosopical issues need to be discussed first.

Essential Definitions

The most obvious place to start is with probably as many different definitions of this concept as there are people doing
research in it. Nonetheless, there is general agreement that AI is a branch of advanced engineering, though not to be confused with the study of computers, which is computer science. Instead, AI is
a study of computer programss Boden, 1977). AI is also a cognitive science conlanguage (Papert, 1980). It has also been dentified as one of the three leading technological breakthroughs of modern
times along with genetic engineering and
microelectronics (Bernhard, 1980). Definitions from leading researchers in
the field begin to explain its scope and purposes somewhat more specifically. University of Sussex, defines AI as the
study of intelligence as computation or he development of a systematic theory of Similarly, Seymour Papert, a mathematician with an extensive background in educational psychology, describes AI as
the use of computational models to gain in it as a souman psychology and reflect make mechanisms emulate human in-
telligence (Papert 1980). Robert Bernhard telligence (Papert, 1980). Robert Bernhard
suggests that AI is the method by which

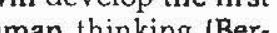
another perspective by defining AI as the

Laura Kann is a graduate student in the Faculty of Education, The University
of Manitoba. totality of atternpts to make and under-
stand machines that are able to perform
tasks that until recently only human be-

ings could perform, and to perform them
with the effectiveness and speed comparable to a human (Banerii, 1969). Donald Fink suggests that AI be defined very functionally as a) the ability
machines to organize information inte meaningful patterns and to recognize,
store, recall, and manipulate such patterns in playing games, solving problems, answering questions and in controlling
the actions of other mechanisms; $b$ t the ability of a machine to respond to patterns
of stimulation, particularly those not forof stimulation, particularly those not for-
seen in its design; and cl the observed performance of such machines as measured by comparison with or in competition against human intelligence (Fink, 1966).
However, the above definitions not withstanding, the most quoted and concise
definition is that of Marvin Minsky of MIT who defines AI as the science of mak ing machines do things that people need in-
telligence to do (The Seeds of Artificial In-

Another way to look at AI is to examine be easily defined as synthetic, man-made, or unnatural, terms most people apply to telligence" simply and satisfactorily are considerably more difficult. Nonetheless. it is necessary to confront this definitional the imrounding it.

Christopher Evans in The Mighty
Micro (1980) defines intelligence as the ability of a system to adjust appropriately to adjust, that is its degree of versatility, the more intelligent that system is. As a general working definition this one is suf-
ficient, but it does not deal with the more subtle facets of intelligence that are necessary for a true understanding of the che mine a system's degree of intelligence. terms, they apply equally to all biological systems as well. The first key factor is
data capture ability, which is a system's data capture ability, which is a system's
ability to extract information from the environment. Another important aspect of intelligence is data storage ability, that is,
the ability of an entity to store information once it is captured and then refer to it in the future to improve its ability to adpart of intelligence is processing speed.
This refers to the speed at which a system This refers to the speed at which a system can process infor
tween basic units.

probably the most in, the fourth factor, is probably the most important factor of in-
telligence. It can be described as the ex- tent to which a system's software can be cy or how an entity adjusts to novel hap ranse size and range of programs with which a system can b cessor can cope. For all six key factors mentioned the more advanced they are in a system the more intelligent hal system
is. They can be used as a framework to judge one system's intelligence in co parison with another's.

ntelligence, Thinking

and Learning

Man has evaluated intelligence in
various ways for centuries. During the last sixly years the most common metho on a scale from one to two hundred. For hose not keen on the idea of a computer not earn more than a mere fraction of a However, it is also important to remember that man has had several hundred million years to develop, while comyears, and the field of $\mathrm{AI}$ even less. Moreover, at this point AI research is only concerned with making a computer in
telligent. and has had to put equal effort into developing, such as reproduction,
defense, mobility, socialization, repai computers. Regardless of this present
situation, what should be obvious is that the term "intelligence" is a complex one indeed and not one to be used lightly. Consequently, it will be used in quota
tions throughout the rest of this article. Another issue of semantics the $\mathrm{Al}$ field deals with concerns the concept of perennial question: can competers thing Alan Turing, the British genius and the term precisely nor answering the question unequivocally, did propose a solution that has generally settled the
issue [Evans, 1980|. His solution took the form of a test now called the Turing Tes! on the idea that humans infer what others are thinking by the kind of conversation they can have with them

humans and The basically involves two serves as the judge or tester and in conhuman and to the computer being evalu-
ated. The judge cannot know in the beginning which terminal is connected to which, but by lyping messages into either
terminal and by receiving messages back factor of intelligence is software efficien. being intelligent, it should be a coms would and maintenance are not of concern to nected by computer terminals to the other is to try to decide. A stupid computer will
be easily revealed as such and the human will have no difficulty identifying it. On the other hand, if the judge cannot determine which terminal is connected to the passed the test and could bill have thinking machine. To date, thou repeated attempts have been made, no computer has passed the Turing Test un-

This has only served to fuel the fire of machine. Their arguments were first
mats categorized by Turing and are essentially 作 1) The Technolovans, 1980). Man is a creation of God, and has been given a soul and the power of conscious thought.
Machines are not spiritual beings, having no soul and thus

must be incapable of thought.
2) The Head in the Sand Objection This is really not an argumen but rather an expression of
wish that it never will, such s 'what a horrible idea!'

3) The Extra Sensory Objection trasensory perception and if it were is some way a function
of human brains, then it can

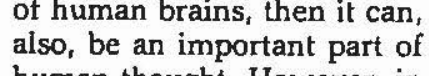
human thought. However, in proving that computers are

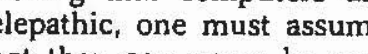
able of thinking.

4) The Personal Consciousness Objection - Not until a compule pose a concerto because of thoughts and emotions felt not by the chance fall of symwritten it, can a machine be

5) The Unnsidered to be thinility Objection While humans behave and hink unpredictably, comto a specific set of rules and operale only according to a specific script, therefore ly human ability.
6) The 'See How Stupid They Are' Ob. many limitations computers now have there is no hope

7) The 'Ah But It Can't Do That' Objection - This is an eternally
regressing argument that conregressing argument that con-
tinually adds a new challeng

8) The 'It every time an earlier one is 'It Is Not Biological' Objection the capacity for thought, so

The Mot possibly think. Based on Kurt Gödel's theorem the argument
follows that no matter how powerful a computer is it can

10) Lady Lovelace's Objection - A computer cannot do anything
it has not been programmed Each of these arguments has been refuted by Turing as well as many other proponents of the thinking machine. To available, not that it never will be available (Dreyfus, 1980). Moreover, many computer programs with limited
thinking abilities have been developed as will be shown later. Regardless of which side is right, there
are negative implications for both. For example, if computers were proven unable to think then that would imply that ble, that thinking is beyond the range of rational thought, and that those who do
think must contain a non-mechanical or non-physical mysterious something. On the other hand, if computers were prove able to think, then man would be merely a a machine (Kugel, 1979). Both options pose interesting dilemmas, which is why
the controversy is so heated at the present. cept of learning. Just as the degrees of intelligence and thinking ability are used to evaluate an AI computer program so is its
ability to learn. The term learning is typically defined as the capacity of quence of experiences [Michis, 1974]. However, the controversy does not con-
cern this definition, but rather the theories for how learning, particularly the learning of language, takes place. AI wort relation between linguistic ability an ing child. Questions concerning the domain-specificity of certain abilities, their relationship to particular brain slictures, and their extent of innateness "intelligence." Typically, either the traditional Chom.
skian or Piagetian perspectives are used as CANADIAN JOURNAL OF EDUCATIONAL COMMUNICATION frameworks for the AI computer pro-
grams. According to the Chomskian view grams. According to the Chomskian view
each child is born with a definite linguistic competence that is extremely specinc to language, has little overlap
with other congnitive abilities, and is determined by innate biological struce tures. In contrast, the Piagetian perspec-
tive maintains that linguistic competence shares the major congnitive processes
with other intellectual domains and is ex plicable in terms of the psych ly on unstructured experiences IThe
Seeds of Artificial Intelligence, 1980. Regardless of which point of view ever the issue. For no complete model human intelligence can ever be devised without a clear theoretical framewo
upon which to base it. Consequently, only a very few AI programs at this time exObviously the issues surrounding the solved. As a result, their effect on the ac tual work done is great and will remain of the primary areas toward which AI confronts many of these issues directly, is education. To fully appreciate the impaa education this paper will review the present and potential uses of computers in

Computers in Education

The use of computers in education has traditionally been in just two domain
(Sugarman, 1978). The first of these is the use of computers for class schedulin record keeping. The other use of computers in education is computer aided in tion. CAI was first introduced into educalion in higher education and industria puters were still quite large, very slow standards. While considered to be revolutionary at the time, CAI never fulfilled its sent day computers those used initially

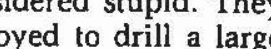
number of students in memorization exercises or to present material in small highly structured pieces, each idea
building on the last, and each piece ntegration. Today in primary and seconforeign language and social classes
studies. At the university level many introductory courses in mathematics or physics utilize the traditional
supplement to regular lectures. 


\section{CHILD MOLESTATION} NOT

\section{AN EASY TOPIC}

Here are two films that approach this theme in a sensitive, non threatening manner which wil assist teachers and resource people to teach children to child sexual abuse.

Just released, BETTER SAFE THAN SORRY II reinforces the three rules for children to remember whenever they are confronted with a situation that is unfamiliar or possibly dangerous. This title, designed specifically for primary grades (ages 5- 9), has been produced as a result of the overwhelming SUCCesS of BET

Released in 1978, BETTER SAFE THAN SORRY dealt with the same topic for childre ages $9-14$ and has been effectively used by public libraries, schools, various community agencies including Block Parents, children's aid societies and police depart ments across Canada.

BETTER SAFE THAN SORRY (Ages 5 - 9)

BETTER SAFE

THAN SORRY

(Ages 9-14)

Available for preview for purchase consideration. Phone or write today.

Marlin Motion Pictures Ltd. MMn Sulie 200, 211 Walline Avenue (416) $272-4100$ Sulle 1212,666 S1.James Stroel
Winnipeg, Manitoba R3G $3 J 6$
(204) 774-0632
Regardless of their specific function most of the early CAI programs have two
detrimental characteristics (Raphael,
19761. First, only one-way communication 1976). First, only one-way communication
is allowed. Material is presented in a passive manner and the student is not allowed to interact with it in any original way. Secondly, because the computer does not allow significant two-way comto think. Many people feel that this is very detrimental to a student's natural in
itiative, originality, and creativity itiative, originality, and creativity.
Moreover, only a few studies show that students gain significantly from the factual information presented by CAI. With
these restrictions in mind it is obvious why CAI's popularity
in the late Seventies.

in the late Seventies.
Fortunately, work in AI has progressed
to such a point that some computer pro. rams, while not yet capable of passing the Turing Test, have definitely become the second chance CAI was in desperate Applying AI to CAI

The new programs produced by AI
research are based on the belief that highly intelligent, empathetic. personal
tutor can enhance the intellectual development of children, even if it is not a Furthere a computer (Naphael, 1976 hat for learning to take place there is more involved than merely placing infor mation in a student's memory (Norman are highly sophisticated and have attempted to incorporate many of the best characleristics of the best human
teachers. Criteria for an effective AI proteachers. Criteria for an effective AI pro-
gram for "intelligent" CAI include the ability to respond to two-way communication; to decide whether to generate a par-
ticular display; to test knowledge of a certiain concept that previously posed problems to the student; to terminate an in molivation, or competency diminishes; to
delermine a sequence of experiments delermine a sequence of experiments
needed for the student to gather the best information: to select both difficult an feedback dynamically; to improve performance over time; to possess a wide range
of behavorial goals for the learner; and to present a structural description of the sub ect matter and performance criteria (Oplications of AI programs that have arisen
from these criteria for "intelligent" CAI While none are entirely exclusive of any other, each type does offer a slightly different emphasis or perspective.
The most successful and most widely implemented and evaluated AI programs
for educating children are based on the for educating children are based on the
principie that the child should control the computer rather than letting the com-
puter control the child, as it traditionally does. A specific example of this, using a
anguage called LOGO Seymour Papert and his colleagloped by Artificial Intelligence Laboratory and Computer Science Laboratory at MIT during the early Seventies, Turtle Geometry
is probably the first AI program designed particularly with the needs of children in mind. The language, LOGO, is non-
ming based predominantly on symbols, but most imporlantly, sophisticated enough to puter languages. The Turtie is, as Paperl describes it, an "object to think with"
(Papert, 1980, p. 11). More concretely, the (Papert, 1980, p. 11). More concretely, the
Turtle is a computer controlled cybernetic Turtle is a compuler controlled cybernetic be triangle on a computer screen or a
mechanical object. The Turtle robot can run on the floor with a pencil in its center run on the floor with a pencil in its center
which can be lowered so that the turtle leaves a trail behind itself. Overtly, to draw geometric shapes of the teacher's $s$ or their own choosing. This activity
leaches them many principles and concepts of geometry. Indirectly, and probably most importantly, the children
learn to verbalize their ideas in a concise manner, divide a task into manageable solutions progressively. In general, what
the children develop as a result of their work with the Turte is a very
sophisticated style of problem solving apsophisticated style of problem solving ap-
plicable to any other school subject as Moreover, they truly enjoy learning this way, which is something that cannot
often be said for traditional teaching often be
methods. A second use of "intelligent" computer
programs is called mixed initiative computerized educational instruction the computer acts as an active partner in the student's learning process. It does not
merely feed facts to the student like the merely feed facts to the student like the
old CAI programs, nor is it programmed exclusively by the student as with Turtle fairly extensive knowledge base to
facilitate the student's acquisition of the material. They can ask questions of well as answer questions posed by the student. Furthermore, these programs can understand natural language commands
to a fairly sophisticated degree, sense stupace of a course, and guide the work to areas the student needs the most help with.
One example of this type of
"intelligent" program is called SCHOLAR (Raphael, 1976). SCHOLAR's specific do. main is South America geography and restricled, its knowledge base of the

VOLUME 12, NUMBER 3, 1983 ferent conditions in a kinetics problem.
the "intelligent" computer can do instantgest further areas of exploration. Similar puter programs discussed, these program encourage student initiative and general A fifth way programs developed by AI
research are being utilized for education is in teaching foreign languages (Raphael,
1976). In one instance the computer can operate a slide projector and a tape recorder, so that the student can hear the
new word pronounced correctly, while at the same time associate it with an appropriate illustration. The number of
words or the speed at which they are presented can be altered by either the computer or the student, for both are work. Once again good study and problem solving skills are em-
phasized. More technically advanced programs use visual representation of contrast inpul by teacher and students or especially helpful to students concerned with getting the proper accent for each word. These programs have also been us
ed quite successfully to heip deaf ined quite successfully to heip deaf in
dividuals to learn to speak. Traditiona methods of depicting the appropriat
sounds have often been widely misinter preted by the deaf person and have thus resulted in very poor speech patterns.
The sixth use for the new "intelligent" computers in education is computerized homework (Raphael, 1976). These programs, often used in conjunction with
math classes, present problems for math classes, present problems for
students to work out. As students improve the difficulty of the problem increases. Each problem is composed of randomly selected numbers so that lessons can be
repeated without the exact same problems being presented. Should the students find a certain problem par-
ticularly difficult they can ask for clues from the computer, or the computer will
revert to an easier but similar problem revert to an easier but similar problem
and will slowly guide the student to the correct answer of the more difficult proshow that more homework is complete in a much more enjoyable way, which A final use for the "intelligent" con puters developed by AI is the one most enjoyed by the students. Authoring pro-
grams allow students to create their own computerized lessons for other class
coms ons members to use (Raphael, 1976). This activity requires students possess a
thorough understanding of a topic with a computer language or at least an
with natural language, and most importantly, natural language, and most importantly,
hebly developed problem solving skills to
debug the programs so that others can shape of curves as certain variables benefit from them. As with all the other
uses for "intelligent" computers the problem solving skills are emphasized
because of their applicability to all facets hand.

The Benefits

These seven examples of the use of
for CAI demonstrate the many benefits that students could receive if these pro grans were to be implemented widely in
stead of in just the few laboratories an experimental settings now availab Specifically, the benefits of these pro-
grams in education can be summarized a First, they can reduce the number society becomes more reliant on our puters those who can interact competen definite advantage over those who can-
not. It is important that children be introduced to computers at an early age an occur. Second, they can create an oppoown thinking in a very helpful way (Boden, 1977). In order to program computer and then debug the program rather than a self defeating, negative on (Bregar, 1980). Furthermore, they must their reasoning, future plans, and the mistakes they have made. Few other
school exercises require such precise and in depth analysis of the thought proces (Raphael, 1976). Consequently, the stumechanical thinking and is able to a king is an confidence about the ability to choose cognitive style that suits the problem, no
mention the realization that there is such a thing as a cognitive style in the fir place. This is not to say that mechanica thinking is necessarily the best approach
though it may be in a mathematics class, but merely that through work with "in-
telligent" computers students will have the opportunity to learn to think articulately about their thinking with Third, AI programs can produce an improvement in the understanding of the A great number of students, particularly females, grow up with a serious fear and matically oriented. Conmonly called in reparabbly separate the humanities from the sciences within society. Two cultures arise from this situation, each set on two. An early introduction and competenbecome a natural vocabulary, not in op-
position to but complementary to the 
traditional linguistic language. As a result
the gulf between the humanities and sciety could relire the cond artmenter ized view of knowledge and learning and
inslead see how well each "side" could benefit the other. Less abstractly. students can realize how well each subjec much each has in common, for there are very few subjects that could not be taugh lo al least' a minimal degree with an
telligent" computer program 1980). Fourth, these programs should pro
duce an increase in the degree of studen participation (Raphael, 1976). "Intellgent" computer programs by their very
nature require a great deal of active student involvement. No longer can a stuteacher's lecture. Each idea presented by a computer must be acted upon by the charge of the programming even more in. head in acquiescence will not encourage computer to continue. Undoublably, this sharpening the concentration and attention spans and by reinforcing the idea tha learning is most productive when it is an

active process.
Whether or not AI's potential to
positively effect education will be realized
and can only be speculated. Though the issue involved are many it is clear that any talk
of the future must be based on the assumption that computer technology has
not reached its peak that growth will conlinue (Evans, 1980). Improvements are needed in the programs' abilities to res-
pond to natural language and in underpond to natural language and in under
standing of the human thought and reasoning processes in order for the pro-
grams to be truly interactive and ''intelligent."

Some Objections and Concerns Opponents to widespread "intelligent"
computer use in the classroom fear that computers will take over the teacher's are a long way from possessing all the necessary traits required to abolish the Teaching profession as it is today. Noneas
theless, computers will be used increas ingly to supplement human lectures, proinfinite patience, and to keep lessons moving at a pace beneficial to all
(Raphael, 1976). Even if computers were to gain the technological sophistication a drastic change would likely occur very slowly to many impending factors is
educational institutions \{Sugarman, 1978 ). Undoubtably, the classroom is an artificial and inefficicient learning environ-
ment, but one that was forced out of necessity to develop because certain
essential subjects such as mathematics essential subjects such as mathematics
and writing could not be assimilated in in- "intelligent" computers capable of pass'ing Turing's rigorous test would pers vironment so that the knowledge schools now try to teach could be learned witho human medialed instruction (Paper, Another concern of the critics of AI's
applications to education is the present lack of standards by which computers
operate in the classroom. They feel that any teaching tool professing to be as implemented widely without some kind of protective restrictions. While Orwellian images of children 'running
wild,' 'drugging themselves,' or 'making life impossible for their parents' are probably exaggerated, they do exemplify an area in great need of attention (Papert, cience and the real nature of learning is understood [Evans, 1980). Simple solu tions in the past, such as Skinner's
teaching machine, have been insufficien and have probably done more to confuse than to resolve the problem. At present teachers, AI researchers, and ad ministrators subscribe to their own per-
sonal theories of learning regardless of Their actual appropriateness to the
specific teaching situation. Only time can tell whether or not those with the power will have enough. foresight and insight 10 One other major issue raised by AI's opponents is whether or not the ability of people to do simple calculations will be
lost due to the computer's greater efficien$\mathrm{cy}$ and accuracy with computational skil detrimental because, though at this point it is impossible to tell, many people fee matical powers are already inhibited by computational rules. "Intelligent" computers, they argue, will free students from
the need to learn these unnecessary skills he need to learn these unnecessary skills hey can tackle higher levels of learning possible that as computers become more intelligent" student intelligence will also
increase. These more "intelligent" computers in a never ending upward
spiral (Raphael, 1976). While this totally imitless growth in computing is neith it is surely possible. Conclusion

Even though AI's opponents presen tention, it appears they will do little to tional applications. Consequently "intelligent" computer use in the classroom
will probably have an even greater effect ch the intellectual development of
children than any other teaching tool or echnoliogy, including the television,
previously devised (Papert, 1980). Obviously, the issues discussed earlier concerning intelligence, thinking, and learn-
ing will need to be settled and many technological and social obstacles must be overcome. However, with the present dis-
Ulusionment with the current school system and the promises that Al's applica pears to be stopping the eventual wide. spread use of artificial intelligence in References

Banerji, Ranan B. Theory of problem telligence. New York: American Elsevier Publishing Co., Inc., 1969.

Bernhard, Robert. An electronic adviso ber 1980, 39-43. Boden, Margaret A. Artificial intelligence and natural man. New York Basic Books, Inc., 1977.

Bregar, William S., and Forley, Arthur $M$. computer-based instruction. Journal of Computer Based Instruction, May 1980, 6(4): 106-114

breyfus, Hubert L. Why computers can March 1980, 6(3): 72-78.

Evans, Christopher. The mighty micro. Canada: Hodder and Stoughton, 1980. Hnk, Donald $G$. Computers and the Books, 1966.
Kugel, Peter. The controversy goes on: can computers think? Creative Co Michie. Donald. On machine intell gence. Great Britian: W. and J. Mackay Limited, 1974. Norman, Donald A., Studies of learnin systems. Paper for the University of California at San Diego, Center for
Human Information Processing, 1979. Human Information Processing, 1979 .
Offir, Joseph. Adoptive comput assisted tutorials: a cybernetic approach to optimization with mechanics. Paper for the Navy Personnel Research, Developme Conter, Papert, Seymour. Mindstorm
York: Basic Books, Inc., 1980 . Raphael, Bertram. The thinking com puter: mind inside matter. San Fra Sturgeon Theodore. Venus plus $\mathrm{X}$. York: Dell Publishing Co., 1960 . Sugarman, Robert. A second chance for computer-aided instruction.
Spectrum, August, 1978, 29-37.

The seeds of artificial intelligence Resources Information Center, Rockville, Maryland, National Institutes of
Health, Department of Health, EducaHealth, Department of
tion, and Welfare, 1980.

VOLUME 12, NUMBER 3, 1983

\section{BOOK REVIEWS}

The Computer in the School: Tutor. Tool, Tutee. Robert P. Taylor (ed.)
Teachers College Press, 1980

Information Technology: Innovations and Applications. Bernard S. Sheehan
(ed.) Jossey-Bass Inc., 1982 Meeting Learners' Needs Through Guide to Programs. Raymond J. Lewis American Association for Higher EducaThe Coming Information Age. Wilson
P. Dizard, Ir., Longman, 1982 . By Paul Hurly

The bountiful harvest of recent books education and society leaves educators and educational administrators with few following is a sample of some of the best of the new crop. most in. Taylor gathered five of the most innovative educators using com
puters in the United States - Alfred Bork Thas Dwyer, Arthur Luehrmann, Seymour Papert and Patrick Suppes - to
discuss their philosophies and approaches in The Computer in the School: Tutor modal framework for analyzing the educational role of computers which As a tutor the computer tests student
Ans As a tutor the computer tests student
knowledge, provides remedial material, ool the computer is programmed to perform such functions as simulations or receives the greatest focus in the book, is when the student tutors the computer via

\section{AMTEC Board of Directors}

President:
Tom Rich

Media Coordinator

P.E.I. Dept. of Education

P.O. Box 2000
Charlottetown, P.E.I. C1A 7N

Past President:

Lou Wise
Coordinator of Teaching Aids

Toordinalor of Teaching Aids
Toronto Board of Education

Don Mills, Ontario M3A 3C3

CANADIAN JOURNAL OF EDUCATIONAL COMMUNICATION

President Elect:

Editor:

Dr. Denis Hlynka ed, Taylor's text provides an uplifting
glimpse of the potential future direction of glimpse of the potential future direction of
schooling and formal learning in North America. technologies are scrutinized by the authors gathered by Sheehan in Infor Applications. By itself this book does nol of the new technologies to descrist thon readers who are less well informed about The strength of this book is its attention to The strengher are made regarding the use of educational media and information technology.
Manfred Kochen and Carl Adams Manfred Kochen and Carl Adams
discuss the challenge of planning for the discuss the challenge of planning for the
implementation of information technologimpact on society. They also identify some benefits of information technologies for planners. Richard Evans provides an
update of his 1968 study on resistances to innovation in higher education and sug. gests several pragmatic steps for overcoming the blockages. Despite the learned opi-
nions of Sheehan and his colleagues, however, educational technologists may have a far greater impact on the typing
pool than in the classroom domain of the professor. In Meeting Learners' Needs Through has provided impressive evidence that innovalive media-based educational promail and telephone surveys Lewis comping ed summaries of 70 educational programs at the college and university level which
use CATV, interactive CATV, teleconferencing, videoconferencing, computers and computerconferencing, televisio
and videotape media to serve the needs of

wide range of learners. Prose and poinl ange of standard topics such as educational mission, problems encountered, structure and observations about distance planners and administrators seeking models for implementing innovative telecommunication-based learning strategies
for their institutions. Planning for the successful implementa-
tion of information technologies, argues Wilson Dizard, Jr., requires strong central

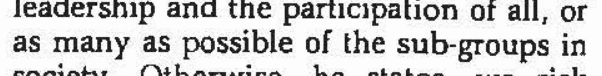
society. Otherwise, he states, we risk making decisions which will benefit elites

In The Coming Information Age development of computer, satellite and telephone communications in the United economic preeminence of the telecommunications sector in the $1980^{\prime} \mathrm{s}$. bureaucratic communication planning similar points made by John Wicklein in his largely ignored but insightful, Ele on the dangers awaiting society if cordisarray, regarding telecommunications policies persists, will give Canadians considerable cause for anxiety. The rece
track record of Francis Fox's DOC ma darins, and the CRTC, typify the frenetic
approach to planning Dizard advises we must foresake. In this advice there is also
a strong message for educational plan-

Head, Dept. of Educa College of Education University of Saskatchewan
Saskatoon, Saskatchewan S7N OWO

Secretary Treasurer:

Guy Leger
Asst. Superintendent of Curriculum
Metropolitan Separate School Board Metropolitan Separate School
80 Sheppard Ave. E.

Faculty of Education

University of Manitoba
Winnipeg, Manitoba R3T 2N2
Director:
Bill Hanson

Salerials Calgary Board of Education
C10 - 9th Street S.E. Director: Director: Director of Instructional Media 675 West Hastings
Vancouver, B.C. V6B 1N2 Director:

Danielle Fortosky
Director of Education

Television Production

University of Saskatchewan
Saskatoon, Saskatchewan S7N ow0 